\title{
TRADISI TALE DALAM KEHIDUPAN MASYARAKAT KERINCI
}

\author{
Ayuthia Mayang Sari \\ Program Pascasarjana \\ Institut Seni Indonesia Surakarta \\ JI. Ki Hadjar Dewantara No. 19 Kentingan, Jebres, Surakarta, 57126 \\ Email: ayuthia@yahoo.com
}

\begin{abstract}
ABSTRAK
This research focuses on the subject matter of Tradition of tale (Traditional Song) in the life of Kerinci People. It aims to see and formulate the existence of Tale. In understanding it, qualitative research methods are used so that the data obtained is descriptive of the behavior of those observed. This study uses a phenomenological point of view that is seeing phenomena as appear appropriate in the field. From the result of the study, it was found that tale is a song of the Kerinci folk in the form of a rhyme. Tale is present in various traditional arts in Kerinci. The tale tradition can be classified according to how to sing it; they are tale that is sung without equipping by music instrument, tale in dancing and tale that is sung equipped by using music instrument.
\end{abstract}

Keywords: Tradition, Tale, Kerinci.

\begin{abstract}
This research focuses on the subject matter of how the tale tradition in the lifes of people in Kerinci. It aims to learn and formulate the existence of tale. The qualitative research method is used to examine the problem in order to present descriptive data relating to the behavior of the people observed. This study uses a phenomenological point of view, namely seeing the phenomena as they appear in the field. The result of the study shows that the tale represents Kerinci folk song in the form of a rhyme. The tale is present in various traditional arts in Kerinci. The tale can be classified based on how it is sung, namely the tale that is sung without musical instruments, tale in the dance and tale that are using musical instruments.
\end{abstract}

Keywords: Tradition, Tale, Kerinci

\section{A. Pengantar}

Kerinci merupakan daerah yang kaya dengan kesenian tradisi. Kesenian tradisi yang dapat dinikmati masyarakat sampai pada saat ini adalah seni musik dan seni tari. Kesenian tradisi tersebut ada dan bertahan dalam kehidupan sosial masyarakat Kerinci. Sebagaimana yang dituliskan (Rohidi 2000, 13-14):

"Kesenian ada, berkembang, dan dibakukan, di dalam/dan melalui tradisi-tradisi sosial suatu masyarakat. Seperti halnya dengan unsur-unsur kebudayaan lainnya, kesenian juga berfungsi untuk menopang dan mempertahankan kolektivitas sosial. Kesenian adalah milik masyarakat, walaupun dalam kenyataan empirik yang menjadi pendukung kesenian itu adalah individuindividu masyarakat yang bersangkutan. Dalam kenyataan empirik, kesenian dapat dilihat sebagai cara hidup, yang bertalian dengan keindahan, dari para warga masyarakat."

Kesenian tradisi di daerah Kerinci merupakan buah dari tingkah laku masyarakat Kerinci yang dihadirkan oleh masyarakat dan dipertontonkan untuk masyarakatnya sendiri. Ragam budaya masyarakat Kerinci memiliki fungsi dalam tatanan masyarakatnya. Tale sebagai salah satu kepemilikan budaya masyarakat Kerinci menjadi suatu wahana komunikasi yang memberi arah pada masyarakat pemakainya, dengan acuan kepercayaan yang diyakininya secara turun-temurun sebagai pencarian identitas budaya masyarakatnya. Dalam kehidupan kesenian tradisi masyarakat Kerinci, seni musik lebih mendominasi dalam berbagai seni pertunjukan. Seni musik yang menjadi identitas masyarakat Kerinci adalah seni musik vokal yang biasa disebut tale. Tale tergolong 
dalam tradisi lisan masyarakat Kerinci yang dapat dijumpai dalam berbagai pertunjukan.

Tale merupakan tradisi oral nenek moyang sejak dahulu yang dilagukan dengan rangkaian nada yang khas. Sejalan dengan hal tersebut, (Peursen 1976, 11) mengemukakan bahwa tradisi dapat diterjemahkan dengan pewarisan atau penerusan norma-norma, adat istiadat, kaidah-kaidah, hartaharta. Tetapi tradisi tersebut bukanlah sesuatu yang tidak dapat diubah: tradisi justru diperpadukan dengan aneka ragam perbuatan manusia dan diangkat dalam keseluruhannya. Manusialah yang membuat sesuatu dengan tradisi itu: ia menerimanya, menolaknya atau mengubahnya.

Tale sebagai kesenian tradisi digunakan sejak dahulu hingga sekarang dengan mengalami perubahan-perubahan dalam penggunaan dan penyajiannya. Tale tergolong pada nyanyian rakyat Kerinci. Menurut Jan Harold Brunvand (Danandjaja 2007,141 ), nyanyian rakyat adalah salah satu genre folklor yang terdiri dari kata-kata dan lagu yang beredar secara lisan di antara kolektif tertentu dalam bentuk tradisional serta banyak mempunyai varian. Hal ini sesuai dengan tale yang terdiri dari kata-kata dan lagu dan beredar dalam lingkungan masyarakat Kerinci.

Pada saat ini tale masih dapat dijumpai dalam berbagai kesenian di Kerinci, namun tidak banyak orang yang mengetahui keberadaan tale tersebut, bahkan ada yang menafsirkan semua kegiatan musik vokal adalah tale, padahal tidak semua musik vokal dapat dikatakan tale dan tale hadir di beberapa kesenian tradisi. Hal ini menjadikan tradisi tale dalam masyarakat kerinci patut dirunut kembali keberadaannya.

Metode yang dilakukan untuk merumuskan fenomena ini adalah dengan metode penelitian kualitatif. Penelitian kualitatif adalah prosedur penelitian yang menghasilkan data deskriptif berupa kata-kata tertulis atau lisan dari orang-orang dan perilaku yang dapat diamati (Moleong 2002, 3). Tradisi tale dalam kehidupan masyarakat Kerinci dilihat dari sudut pandang fenomenologi yang diperkenalkan Edmund Huserl yaitu berawal dari cara pandang berdasarkan fenomena yang tampak apa adanya (Sutiyono 2011, 97).

\section{B. Pembahasan}

\section{Pemahaman Tale bagi Masyarakat Kerinci}

Banyak pemahaman tentang arti dan makana tale dalam kehidupan masyarakat Kerinci. Seperti yang dituliskan Mistortoify $(2015,181)$, fenomena semacam ini telah menjadi bagian dari tradisi lisan. Penafsiran beragam tentang suatu istilah yang masih berada dalam satu kultur. Esensi pengertian bisa saja sama, tetapi detail terminologinya kurang tepat sama. Fenomena ini terjadi pada penafsiran terminologi dan peristilahan di pulau Madura mengenai Kejhungan. Kasus yang sama juga terjadi pada penafsiran tale dalam masyarakat Kerinci, maka untuk penafsiran terminologi tentang tale yang ideal dapat diperoleh dari orang yang memiliki otoritas dalam budaya musik Kerinci dan ahli bahasa lokal.

Berdasarkan terminologi, ada beberapa pendapat mengenai arti tale ${ }^{1}$ bagi masyarakat Kerinci. Pertama, tale berasal dari kata 'tahlil'. Kedua, tale berasal dari kata talai yang memiliki arti tali atau bertalian. Ketiga, tale sebagai sebuah lagu. Keempat, tale merupakan nyanyian rakyat. Kelima, tale adalah sebuah pantun yang dilagukan. Keenam, tale diartikan sebagai sebuah lagu yang berbahasa Kerinci. Semua pendapat tersebut memiliki pemahaman masingmasingnya.

Tambo Sakti Alam Kerinci Jilid 2 (Zakaria 1984, 58), menuliskan pendapat tentang arti tale. Ada tiga pemahaman yang dipaparkan Zakaria dalam tulisannya. Pertama, tale berasal dari kata 'tahlil' dalam bahasa Arab. Tahlil merupakan pernyataan umat Islam untuk mengatakan tidak ada Tuhan selain Allah, dengan bacaan "laillahaillallah". Bacaan ini kerap muncul di dalam acara keagamaan umat Islam. Kata tahlil tersebut kemudian menjadi tale yang berarti lagu. Mereka menganggap bahwa bertahlil sama seperti bernyanyi dan berirama. Kedua, tale berasal dari kata talai yang memiliki arti tali atau bertalian. Bertalian yang dimaksud zakaria adalah dilagukan terusmenerus dengan bersahutan seolah bertali-tali saja tidak berkeputusan. Ketiga, tale diartikan sebagai sebuah lagu. Zakaria menuliskan bahwa nyanyian/lagu yang digunakan untuk menyeru dan memuji roh nenek moyang disebut tale asyeik ${ }^{2}$.

Pendapat keempat mengartikan tale sebagai nyanyian rakyat. Pemahaman ini dikarenakan tale yang beredar dilagukan oleh rakyat Kerinci, isi nyanyiannya menceritakan tentang kisah kehidupan rakyat Kerinci. Kelima, ada pendapat yang mengartikan bahwa tale adalah sebuah pantun yang dilagukan. Pernyataan ini didasarkan atas tale yang digunakan oleh masyarakat Kerinci, memiliki formulasi pantun. Keenam, penafsiran yang terjadi di kalangan masyarakat awam pada saat ini yaitu tale diartikan sebagai sebuah lagu. Masyarakat awan yang dimaksud adalah masyarakat yang tidak terlalu dekat dengan kesenian tradisional. Mereka menganggap 


\section{GEEAR Jumal Sai isubya}

bahwa semua lagu berbahasa Kerinci merupakan tale $k$ inca $^{3}$, bahkan anggapan ini berlaku juga di dunia produksi lagu daerah Kerinci.

Berdasarkan beberapa pendapat di atas tentang pemahaman tale dalam masyarakat Kerinci, dapat dilihat contoh-contoh yang memperkuat setiap pernyataan tersebut. Pertama, tale berasal dari kata talai sebagai tali, dapat ditemukan di dalam percakapan keseharian masyarakat Kerinci. Misalnya digunakan dalam ungkapan keseharian seperti "ambik talai ndok pangobot tampek beheh, bie beheh ideak bacihe". Kalimat tersebut menggambarkan bahwa talai atau tali adalah benda atau alat yang digunakan untuk mengikat suatu benda. Berarti ada semacam keterikatan antara talai dalam percakapan dengan tale yang dilagukan. Tale memiliki arti bertalian juga dapat ditelusuri pada ungkapan keseharian masyarakat Kerinci seperti "Lmak niang makan iko. Batalai be jeak tadoih"5. Kalimat tersebut bermakna bahwa seseorang yang menikmati makananannya sehingga tidak putus-putus makan. Implementasi dari tale memiliki makna bertalian ada dua yaitu bertalian secara teks lagu dan bertalian secara pelaksanaan. Bertalian secara teks lagu maksudnya adalah teks pada tale menceritakan sesuatu yang setiap baitnya memiliki ikatan cerita dengan bait selanjutnya. Sebagai contoh, dapat dilihat sebagai berikut.

Cinak ini ruponyo ahi

Patut nian buladang bawang

Cinak ini ruponyo kami

Patut nian kami tibuang

Tigo luhah tanah sikudung

Rumah gedang tempat berunding

Kato alah sudah kami tilangsung

Kayo buralih ngan uhang lain

\section{Bukan rakit ngato nak pnoh \\ Buluh tirendam nak pnoh jugo \\ Bukan punyakit ngato nak munoh \\ Rindu ngan dendam nak munoh jugo \\ Tinggi nyo bukik samo di daki \\ Luhah ngan dalam samo ditempuh \\ Tunggu lah kayo ranah kurinci \\ Bialah kami tibuang jauh \\ (Wawancara Pernila, Agustus 2017)}

Terjemahan:

Beginilah rupanya hari

Patut sekali berladang bawang

Beginilah rupanya kami

Patut sekali kami terbuang
Tiga lurah tanah sikudung

Rumah gadang tempat berunding

Kata kita sudah sepakat

Anda beralih dengan orang lain

Bukan rakit namanya jika penuh

Buluh terendam akan penuh juga

Bukan penyakit yang akan membunuh

Rindu dan dendam akan membunuh juga

Tinggi bukit sama didaki

Lurah yang dalam sama ditempuh

Tunggulah kamu tanah Kerinci

Biarlah kami terbuang jauh

Pada bait pertama teks pantun menceritakan bahwa karena orang tidak berpunya, patut saja seseorang terbuang dari kekasihnya. Bait kedua menceritakan bahwa padahal kesepakatan keduabelah pihak telah ada namun si kekasih beralih ke orang lain. Bait ketiga mengungkapkan bahwa bukan penyakit yang akan membunuhnya, tetapi rindu dan dendam terhadap kekasihnya tersebut yang akan mematikannya. Bait keempat menceritakan tentang seseorang akan pergi jauh meninggalkan Kerinci. Inti dari pantun di atas adalah tentang seseorang yang tidak berpunya (bukan orang Kerinci) tidak bisa bersatu dengan orang Kerinci asli, maka dia lebih memilih untuk pergi meninggalkan Kerinci. Dari makna tale tersebut dapat dilihat bahwa bait pertama dengan bait berikutnya akan berkaitan dan membentuk kesatuan cerita.

Bertalian dalam hal pelaksanaan dimaksud yaitu bersahut-sahutan tanpa putus sampai kegiatan yang dilakukan telah selesai. Sebagai contoh, dalam kegiatan mule kumo yang berarti turun ke sawah (menanam benih padi). Para petani memulai kegiatan mule kumo pada pukul 06.00. Selama aktivitas menanam benih dilakukan, para petani melantunkan tale dengan durasi yang cukup panjang. Biasanya tale dilagukan pertama kali oleh salah seorang petani (jantea atau batinao) ${ }^{6}$ sambil petani lainnya mempersiapkan peralatan kerja. Kemudian petale yang lain mulai betale secara bergantian dengan cara basalo jawot ${ }^{7}$. Tale dilagukan sampai pada waktu istirahat datang dan sewaktu berakhirnya kegiatan mule kumo pada hari tersebut (Wawancara, Maryam, April 2018).

Tale yang diartikan sebagai sebuah lagu untuk menyeru dan memuja roh nenek moyang dapat dilihat pada tulisan (Zakaria 1984, 10) bahwa vokal yang digunakan untuk tari asyeik ${ }^{8}$ disebut tale asyeik. Berikut tentang tale asyeik. 


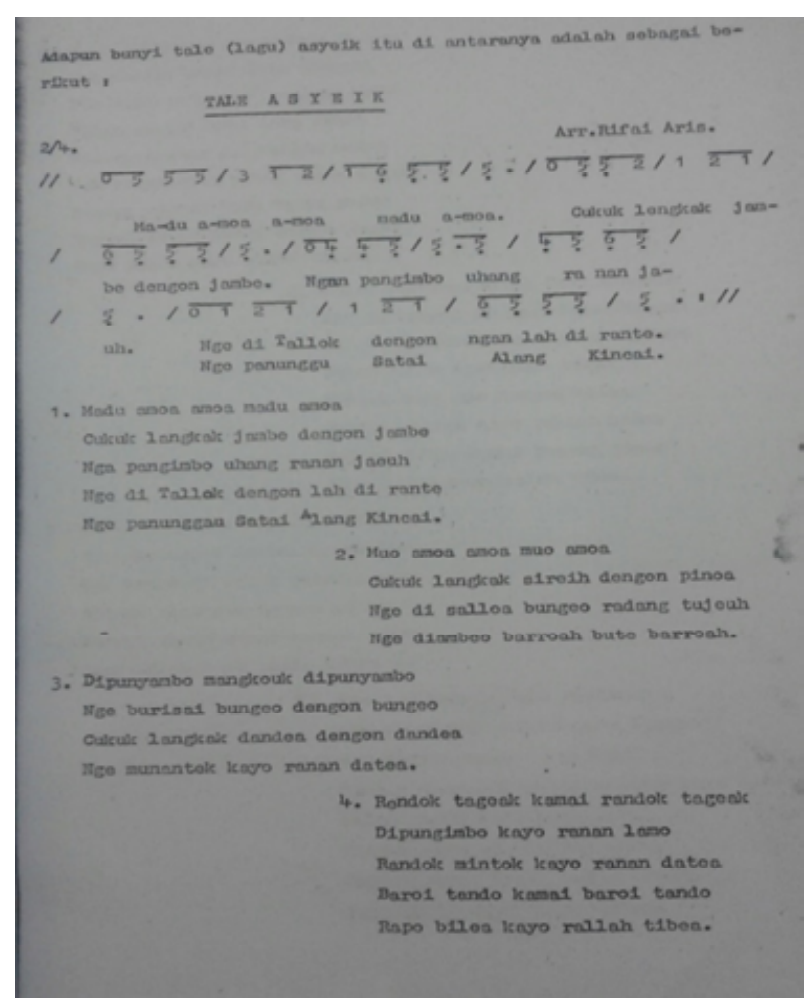

Gambar 1. Teks Tale Asyeik

(Foto: Ayuthia, 2018)

Penyebutan nyanyian dalam ritual asyeik sebagai tale asyeik, mendapatkan beberapa pertentangan dari pelaku dan pengamat seni. Rasmi Rio dan Retchi Angralia memiliki pemahaman yang berbeda dengan pendapat Zakaria. Mereka menyebutkan bahwa nyanyian yang digunakan dalam ritual tersebut tidak dapat dikatakan tale karena tidak mengandung unsur utama pantun yaitu memiliki sampiran dan isi. ${ }^{9}$

Tale juga diartikan sebagai nyanyian rakyat. Nyanyian rakyat yang dimaksud dapat dilihat dari teks tale yang menceritakan tentang kehidupan rakyat dan alam Kerinci. Sejalan dengan hal tersebut, pemahaman lebih mendalam lagi yaitu penafsiran tale sebagai nyanyian rakyat yang berbentuk pantun. Nyanyian yang digunakan oleh masyarakat ini terdiri dari kiasan yang kemudian menghantarkan pada isi teks tersebut yang biasa disebut pantun oleh masyarakat Kerinci. Seperti yang dituliskan (Rampan 2014, 1-2) bahwa pantun merupakan suatu bentuk puisi lama bangsa Melayu yang memiliki sampiran dan isi. Sampiran pada pantun mengandung kiasan, ibarat, peribahasa dan sesuatu yang samar-samar akan dijelaskan isi pantun. Hal ini dapat tergambar dari teks tale berikut.
Dibutanak la di la kaki gunung

Masak ala nasi kayo ae la dikipeh angin, la dikipeh angin $2 x$

llok budi kayo ni ala datung

Bueo dipunakan kayo ae ambik uhang lain, ambik uhang lain $2 x^{10}$

(Zakaria 1984, 67)

Berdasarkan teks di atas dapat dilihat bahwa baris pertama dan kedua merupakan sampiran, baris ketiga dan keempat merupakan isi. Sampiran yang digunakan pada tale, memuat kiasan dengan penggambaran alam dan kehidupan masyarakat Kerinci. Daerah Kerinci yang dikelilingi gunung dan perbukitan serta tradisi masyarakat Kerinci memasak nasi menggunakan tungku, sehingga lebih mengutamakan kekuatan angin untuk menghidupkan api. Isi tale tersebut menceritakan bahwa kesedihan seseorang karena anak datung ${ }^{11}$ menikah dengan orang lain (keluar dari keturunan Kerinci).

Berdasarkan beberapa pemahaman di atas, dalam kehidupan masyarakat Kerinci tale diartikan sebagai sebuah nyanyian rakyat yang berbentuk pantun. Hal ini dapat dilihat dari formula teks tale yang muncul di berbagai musik tradisional Kerinci.

\section{Jenis- Jenis Tale dalam Kehidupan Masyarakat Kerinci}

Berbicara mengenai tale, maka akan berkaitan dengan aktivitas dan pelaku tale. Segala bentuk aktivitas melagukan tale disebut dengan betale ${ }^{12}$. Betale dimaknai sebagai kata kerja yang dilakukan secara impulsif oleh orang-orang tertentu yang memiliki kemampuan melagukan tale. Kemampuan yang dimaksud adalah penguasaan teks pantun untuk mengungkapkan suasana hati atau suasana sekitarnya dalam bentuk lagu.

Aktivitas betale dilakukan oleh petale ${ }^{13}$. Petale merupakan sebutan bagi orang yang menyanyikan lagu pada tale. Petale tidak terikat oleh jenis kelamin. Petale boleh berjenis kelamin laki-laki ataupun perempuan. Petale juga tidak terikat oleh jumlah pelakunya, bisa ditalekan secara tunggal atau banyak orang. Hal ini sesuai dengan tale pada kegiatan yang dilakukan.

Tale pada mulanya dilagukan secara personal oleh masyarakat Kerinci untuk kepentingan pribadi. Aktivitas personal tersebut di antaranya seperti menidurkan anak, menghibur diri pada saat sedih, sebagai sarana mengekspresikan pengalaman pribadi dan kegiatan lainnya yang bersifat individual. Kemudian tale juga dijadikan nyanyian yang tidak hanya bersifat 


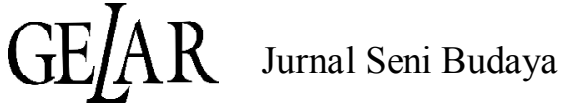

personal, namun juga nyanyian yang bersifat kelompok, artinya digunakan untuk kegiatan yang melibatkan banyak orang.

Dahulu masyarakat Kerinci menyampaikan sesuatu menggunakan tale. Mereka menganggap menyampaikan sesuatu melalui pantun merupakan salah satu cara yang lebih baik dan sopan, sehingga terjalin komunikasi yang baik antar sesama. Komunikasi berpantun ini terjalin seperti di dalam kegiatan bertamu ke rumah tetangga, meminta sesuatu hal kepada orang lain dan pertemuan antar dua pihak yang bersifat resmi. (Wawancara, Rasmi Rio, 20 Maret 2018)

Tale memuat pantun spontan dari petale. Setiap pantun dalam tale dilantunkan dan diciptakan sesuai dengan kemampuan dan penguasaan petale tersebut. Tidak ada pantun yang dilarang dalam tale, selagi tidak melanggar norma dalam bermasyarakat. Maksudnya adalah pantun yang dilagukan memuat kata-kata yang sopan dan pantas untuk dilontarkan kepada orang lain. Bagi petale, pantun yang disampaikan harus memiliki makna dan tujuan yang jelas agar pesan yang terkandung di dalam tale dapat dipahami dan diterima dengan mudah oleh orang lain.

Saat ini tale masih ada dan digunakan dalam kehidupan masyarakat Kerinci. Namun tidak memiliki peran yang penting lagi untuk keseharian masyarakatnya. Hanya beberapa orang yang masih betale. Hal ini dikarenakan kemajuan teknologi yang menyebabkan pergeseran penggunaan tale. Teknologi seakan menawarkan sesuatu yang praktis serta tidak memakan waktu, biaya dan tenaga yang banyak. Pergeseran penggunaan tale dapat dilihat dari masyarakat yang mendiami suatu dusun dan desa di Kabupaten Kerinci. Wilayah yang masih belum banyak bersentuhan dengan masyarakat lain atau dimasuki pendatang, akan lebih mudah untuk dilihat dan diamati keberadaan tale di dalamnya.

Tale memiliki signifikansi dalam kehidupan masyarakat Kerinci pada zaman dahulu. Tale digunakan dalam berbagai kegiatan baik personal maupun kelompok karena tale memiliki hubungan yang erat dengan persoalan sosial budaya Kerinci. Kehadiran tale dalam kehidupan sehari-hari digunakan pada waktu-waktu tertentu sesuai dengan kebutuhan masyarakat.

Tale sebagai nyanyian rakyat yang diwariskan oleh nenek moyang, hadir dalam berbagai musik tradisional Kerinci. Tale sebagai tradisi dapat dilihat dari jenis-jenis tale yang digunakan oleh masyarakat Kerinci. Berdasarkan cara melantunkannya (Sari, 2018: 39) mengklasifikasikan 3 jenis tale yaitu tale yang dilagukan tanpa menggunakan instrumen musik, tale dalam tarian, dan tale yang dilagukan menggunakan instrumen musik.

\section{Tale tanpa Instrumen Musik}

Tale tanpa instrumen musik yang dimaksud adalah tale yang dilagukan hanya dengan vokal. Tale ini ada yang dilagukan secara personal dan dilagukan secara bersama-sama. Tale yang dilagukan secara personal yaitu tale ngasuh anok dan tale mindau. Tale ngasuh anok adalah tale yang digunakan untuk menidurkan anak. Tale ini biasanya dilagukan oleh seorang ibu. Sebelum betale, sang ibu membersihkan badan anaknya dan mempersiapkan buei kain sahong ${ }^{14}$. Dengan tale ngasuh anok, anak yang ditidurkan tidak akan menangis karena pantun dengan irama yang syahdu dapat menenangkan anak dalam tidurnya. Berikut ini contoh teks tale ngasuh anok:

Bideuk tiraih pangayoh sumbain

Mano buleh ka pulou tengah

Indok bureuk apak miskain

Mano buleh anak ku tengah ${ }^{15}$

(Wawancara Maryam, April 2018)

Teks tale di atas mengisahkan seorang anak yang harus sadar dengan nasib hidupnya. Hidup sesuai dengan kemampuan orang tua. Anak yang terlahir dari ibu buruk dan ayah miskin tidak bisa terlalu maju dalam hidupnya. Berdasarkan teks di atas dapat dilihat bahwa ada nilai kehidupan yang terkandung dalam nyanyian penghantar tidur atau tale ngasuh anok.

Selanjutnya, tale yang dilagukan secara personal adalah tale mindau. Tale mindau berarti tale merindu. Tale ini biasanya dilagukan oleh muda-mudi yang sedang merindukan kekasihnya. Tale ini digunakan untuk mengungkapkan perasaan dan menyampai rindunya. Berikut ini contoh teks tale mindau,

\section{Bukeik pintau di sandaran duleang Tempek munanam sikunyeit temau Rumeah kayo duleo dikuniang jangea Kalau rindau pandang ala buleang Runtoung disitau kito butamau Manan rideak nangaih ratai kamai ribea ${ }^{16}$ (Zakaria 1984, 59-60)}

Teks tale di atas adalah bentuk ungkapan kerinduan seorang kekasih yang selalu teringat dan mengharapkan pertemuan. Sang kekasih menangis dengan hati iba karena hanya bisa memandang bulan yang sama meskipun tempat berbeda. 
Selanjutnya, tale juga dilagukan bersamasama. Biasanya tale jenis ini digunakan untuk kegiatan yang melibatkan banyak orang. Berikut contoh tale yang dilagukan bersama-sama:

a) Tale mule kumo

Tale mule kumo adalah tale turun ke sawah. Tale ini digunakan untuk menghibur para petani yang menebar benih di sawah. Tale ini dilagukan dengan basalo jawot ${ }^{17}$ oleh petale jantea dan batinao. Pada mulanya dilagukan oleh salah seorang petale sebagai pembukaan, kemudian di ikuti oleh petale yang lainnya. Seperti yang telah dituliskan sebelumnya bahwa tale ini dilagukan mulai pukul 06.00 hingga pekerjaan telah selesai dilakukan. Tale ini sudah sangat jarang sekali dilaksanakan oleh masyarakat Kerinci.

b) Tale nuei padi

Tale nuei padi adalah tale menuai padi. Tale ini digunakan saat musim menuai padi. Biasanya setiap setahun sekali ada pelaksanaan tale nuai. Kegiatan tersebut dilakukan saat masyarakat Kerinci panen raya ${ }^{18}$. Sambil menuai padi dengan menggunakan alat tradisional yaitu tuei ${ }^{19}$. Menuai padi menggunakan tuei memakan waktu yang lama. Maka tale digunakan untuk menemani petani bekerja agar dengan waktu bekerja yang panjang tersebut tidak terasa lelah. Tale ini dilagukan dengan basalo jawot oleh petale jantea dan batinao. Waktu betale pada saat pekerjaan mulai dikerjakan hingga pekerjaan telah selesai dilakukan.

c) Tale nahik kayau

Dahulu masyarakat Kerinci membuat rumah atau peralatan rumah dengan menebang kayu di hutan. Proses penebangan masih menggunakan cara tradisional sehingga membutuhkan banyak orang dan memakan waktu yang lama. Maka masyarakat Kerinci berinisiatif untuk betale pada saat proses nahik kayau. Pada kegiatan ini, tale berfungsi menemani dan menghibur para pekerja hingga pekerjaan selesai dilakukan. Tale ini dilagukan oleh satu orang atau juga dengan basalo jawot yang terdiri dari petale jantea dan batinao.

d) Tale daheak

Tale daheak berarti tale ladang. Tale daheak adalah tale yang digunakan di ladang untuk menghibur para petani ladang saat bekerja. Tale jenis ini palaksanaannya sama dengan tale nuei padi, mule kumo, dan tale nahik kayau. Tale ini dilagukan oleh satu orang atau juga dengan basalo jawot oleh petale jantea dan batinao. Waktu betale yaitu pada saat pekerjaan mulai dikerjakan hingga pekerjaan telah selesai dilakukan.
Pada dasarnya tale mule kumo, tale nuei padi tale daheak dan tale nahik kayau memiliki banyak persamaan. Persamaan tersebut yaitu dari sisi waktu pelaksanaan, proses pelaksanaan, dan cara pelaksanaan tale. Bahkan pantun yang dilagukanpun memuat pantun yang sama. Perbedaannya hanya terletak pada bagian pembukaan pantun saja. Berikut contoh pantun pada tale-tale tersebut.

Ideak ile ideak ketuang

Sungguh ile kemaro tebea

Ideak butale ideak ketuang

Sungguh betale atai ku ibea

Manan muat batanok inai

Bereh becampo dingan manaih

Manan muat atai ku inai

Geleak becampo dingan tangaih

Ile mudoik menyandan jangkoi

Jangkoi burisoi si benon kaen

lle mudoik dusanak bencoi

Manolah tempeak badeang mungadoi ${ }^{20}$

(Wawancara Maryam, April 2018)

Teks tale di atas menceritakan tentang seseorang yang mengungkapkan perasaan sedihnya dengan betale. Seseorang tersebut mengalami kesedihan karena semua saudaranya membenci dia.

Banyak hal yang masih belum terungkap mengenai jenis tale di atas, namun keterbatasan petale dan narasumber menjadi sebuah hambatan dalam proses penguraian secara rinci mengenai tale zaman dahulu.

e) Tale joi

Tale joi ${ }^{21}$ yaitu tale haji. Tale joi digunakan untuk mendo'akan keluarga yang hendak berangkat haji. Tale ini berisi tentang harapan dan pujian kepada Allah SWT agar keluarga yang berangkat naik haji ke tanah suci terlindung sampai kembali ke tanah air. Tale jenis ini merupakan tale yang mengandung nilai religi karena berkaitan dengan kegiatan agama Islam. Pada pelaksanaannya, tale joi dilagukan oleh belasan hingga puluhan orang laki-laki dan perempuan. Pelaksanaannya dilakukan di masjid dan di rumah keluarga calon jemaah haji. Berikut pantun tale joi.

Dengan bismillah mulo batale

Alhamdulillah mulo badu'a

Laillahaillallah kalemah tale

Sholawatkan nabi tidak boleh lupo

Nagerai yang tigo dilebihkan Allah

Pertamo mekkah kaduo madinah

Baitul Mugaddis tempat katigo

Hajjike baitullah rukun kalimo ${ }^{22}$

(Wawancara Retchia, Maret 2018) 


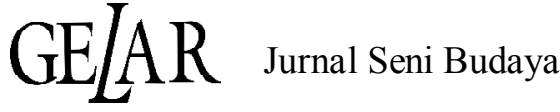

\section{Tale dalam Tarian}

a) Tari tauh

Tari tauh adalah tari pergaulan rakyat Kerinci tepatnya daerah lempur danau. Tari ini disebut tari pergaulan karena bersifat mengajak orang lain untuk menari. Tari ini digunakan pada acara-acara adat seperti kenduri $s k o^{23}$ dan penyambutan tamu besar. Tarian ini ditarikan oleh laki-laki dan perempuan yang sudah dewasa. Musik tari ini menggunakan gumbe ${ }^{24}$, dap $^{25}$ dan vokal yang berupa tale mantau ${ }^{26}$, bahkan juga ada yang menggunakan rebab. Tale pada tarian ini disebut tale mantau yang artinya memanggil dengan suara yang melengking dan lantang. Masyarakat daerah lempur menyebut teks tale ini dengan kata pantau dalam bahasa desanya yang memiliki arti pantun. (Wawancara, Nurcaya, Juni 2018), Berikut pantun pada tale mantau.

Pemuda:

Cubo-cubo klasik julai

Mak tantu padi dengan ganto

Cubo-cubo usik dengan kamai

Mak tantu budi dengan baso

Pemudi:

Lah lamo kami ndok ka koto

Ka koto manjalang pagi

Lah lamo kami nanti kato kayo

Baru kinai taubat ati ${ }^{27}$

(Zakaria 1984, 32)

b) Tari iyo-iyo

Tari iyo-iyo merupakan tarian yang dipentaskan kaum perempuan pada saat acara adat seperti kenduri sko, penobatan orang adat dan penurunan benda pusaka. Musik tari ini menggunakan gendang, gong jantan dan gong betina yang ditabuh oleh laki-laki dan petale dari kaummperempuan. Berikut pantun pada tari iyo-iyo.

rilok tarai kayo sadou rinai

rayun jaroilah saludeung jateuh

rantok kakai kudea dibularoi

Semouk tapijeak rideak ralah matai ${ }^{28}$

(Wawancara Retchia, April 2018)

c) Tari rangguk

Tari rangguk merupakan tari kehormatan. Tari ini digunakan untuk menyambut tamu kehormatan. Suatu kehormatan besar bagi tamu yang disambut dengan tarian ini. Tari ini ditarikan oleh perempuan dengan jumlah penari lebih dari enam orang. Penari tari rangguk melakukan gerakan mengangguk sambil memegang rebana. Musik dalam tari ini menggunakan tiga buah dap, dua buah gong dan tale. Berikut tale pada tari rangguk.

Mulo-mulo kamai dudeuk

Kamai dudeuk sudah dibusiang

Mulo-mulo kamai dimuranggauk

Kamai dimuranggauk ntouk kayo ngan dateang

Ramai urang di tanjon tanoah

Urang silimang di munjuon tanggok

Kamai susung jaroi rangkak sambah

Baroi maoh kamai di ranggouk ${ }^{29}$

(Zakaria 1984, 45)

\section{Tale dengan Instrumen Musik}

a) Tale dalam Seruling Bambu

Tale yang digunakan dalam musik Seruling Bambu memuat berbagai macam pantun pada tale keseharian masyarakat Kerinci. Tale dinyanyikan dengan iringan ensambe ${ }^{30}$ musik tradisi. Namun masih memperlihatkan melodi dan cengkok khas Kerinci. Tale dalam musik ini dilagukan oleh laki-laki atau perempuan dan seringkali dilagukan dengan basalo jawot.

Cinak lah ini rupo ranyo ahi

Patut lah nian dibuledang bawang....2x

Cinak lah ini rupo ranyo kami

Patut lah nian kami kayo buang.....2x

Tigo luhah tanah si kadung

Rumah lah gadang tempat berunding....2x

Kato alah sudah kami tilangsung

Kayo buralih dingan uhang lain....2x

Bukanlah rakit ngato ndak penoh

Buluh tirendam lah nak penuh jugo.....2x

Bukan punyakit ngato nak munoh

Rindu ngan dendam lah nak munoh jugo....2x

Tinggi nyo bukit samo di daki

Samo di tampuh luhah ngan dalam....2x

Tunggulah kayo ranah kurinci

Bialah kami hubungan jauh....2x

b) Tale populer

Tale populer yang dimaksud adalah tale yang dinyanyikan bersamaan dengan orgen tunggal. Tale ini memuat pantun pada tale sebelumnya, namun telah disajikan berbeda sesuai dengan perkembangan teknologi. Sehingga tampak jelas adanya pergeseran nilai keindahan pada tale. Berdasarkan penjelasan jenis-jenis tale di atas, peneliti melihat bahwa tale yang dinyanyikan dengan instrumen musik tampak memiliki perbedaan yang jelas dengan tale-tale sebelumnya. Hal tersebut dapat ditinjau dari sisi eksistensi, penggunaan dan penyajiannya. 


\section{Kesimpulan}

Berdasarkan hasil penelitian mengenai tradisi tale dalam kehidupan masyarakat Kerinci, dapat disimpulkan bahwa tale memiliki pemahaman yang beragam dari masyarakat Kerinci. Ada enam pemahaman mengenai tale. Pemahaman beragam tersebut jika dikaitkan satu dengan yang lainnya memiliki bentuk kesatuan. Dalam kehidupan masyarakat Kerinci, tale diartikan sebagai sebuah nyanyian rakyat yang berbentuk pantun.

Tale merupakan musik vokal masyarakat Kerinci yang dapat dijumpai dalam berbagai kesenian tradisional Kerinci. Tradisi betale dapat dijumpai pada beberapa penggunaan. Hal tersebut dapat dilihat dari jenis- jenis tale berdasarkan cara melantunkannya yaitu tale yang dilagukan tanpa menggunakan instrumen musik, tale dalam tarian, dan tale yang dilagukan menggunakan instrumen musik.

\section{Catatan Akhir:}

1 Tale dalam Kamus bahasa Inggris (1976), memiliki arti hikayat, cerita dan dongeng. Hal ini sesuai dengan tale yang teksnya menceritakan kehidupan masyarakat Kerinci

${ }^{2}$ Zakaria lebih setuju dengan pendapat kedua ini. Namun sangat disayangkan sekali dalam tulisannya megenai arti tale, Zakaria tidak membahas dan menjelaskan alasan yang kuat lebih setuju dengan pendapat kedua. Pendapat tersebut seperti hanya sebuah wacana semata. Wacana tersebut terkesan seperti pemaksaan tafsir yang dikaitkan dengan hubungan keagamaan karena pada saat ini mayoritas masyarakat Kerinci menganut agama Islam. Padahal dalam buku yang sama (lihat hal. 10), Zakaria menuliskan bahwa ada tale yang digunakan untuk upacara menyeru roh nenek moyang. Upacara tersebut telah dilakukan sejak masyarakat Kerinci memeluk kepercayaan animisme. Tentu saja bertentangan dengan pernyataan tale berasal dari kata tahlil.

${ }^{3}$ Kincai merupakan sebutan yang sangat khas bagi masyarakat untuk menunjukan daerah Kerinci.

${ }^{4}$ Kalimat tersebut memiliki arti, "gunakan tali untuk mengikat tempat beras tersebut, agar beras tidak berserakan"

${ }^{5}$ Kalimat tersebut memiliki arti, "Enak sekali makan anda. Bertalian saja sejak tadi"

${ }^{6}$ Jantea merupakan sebutan untuk laki-laki. Sedangkan batinao merupakan sebutan untuk Perempuan.
${ }^{7}$ Basalo jawot sama halnya dengan berbalas pantun

${ }^{8}$ Tari asyeik merupakan tari yang digunakan untuk menyeru, memanggil dan memuja nenek moyang untuk datang pada upacara yang dilakukan masyarakat Kerinci. Upacara ini menggunakan sesajian untuk makanan hulubalang yang dipanggil.

${ }^{9}$ Setelah di analisis, penulis melihat bahwa nyanyian yang digunakan dalam ritual asyeik merupakan sebuah mantra untuk menyeru nenek moyang. Hal ini sama seperti yang dituliskan Sugiarto dalam buku yang berjudul Mengenal Sastra Lama $(2015,91)$ bahwa mantra merupakan sastra lisan yang dimiliki masyarakat Melayu yang diyakini mengandung kekuatan gaib dan kesaktian.

10 Terjemahan tale tersebut adalah sebagai berikut:

Memasak nasi di kaki gunung/ masak nasi karena dikipas angin/ baik budi datung ini/ bawa keponakan kamu sudah di ambil orang lain/.

11 Datung merupakan sebutan untuk adik perempuan dari ayah.

${ }^{12}$ Praktik tale disebut betale memiliki ungkapan lain dalam dialek Kerinci yaitu batala, batale', batalie, batalai dan batale.

${ }^{13}$ Pelaku tale disebut dengan petale. Petale memiliki ungkapan lain dalam dialek Kerinci yaitu patala, patale', patalie, patalai dan patale.

${ }^{14}$ Buei kain sahong adalah ayunan yang dibuat dari kain sarung. Mitosnya, jika anak ditidurkan di atas ayunan tersebut, anak akan lebih aman dan dapat tidur nyenyak.

${ }^{15}$ Terjemahan tale tersebut adalah: Biduk bocor pengayuh sumbing/ mana bisa ke pulau tengah/induk buruk bapak miskin/ mana boleh anak ke tengah.

${ }^{16}$ Terjemahan tale tersebut adalah: Bukit pintu di sandaran dulang/tempat menanam kunyit temu/ ayolah anda duluan, jangan belakangan/ kalau rindu pandanglah bulan/ untung-untung disitu kita bertemu/ mana kami tidak kan menangis hatipun iba.

${ }^{17}$ Basalo jawot sama halnya dengan berbalas pantun.

${ }^{18}$ Panen raya merupakan kegiatan panen besarbesaran yang diadakan masyarakat Kerinci satu tahun sekali. Panen raya melibatkan beberapa pemilik lahan dalam satu dusun atau desa.

${ }^{19}$ Tuei merupakan alat untuk menuai padi atau biasa dikenal dengan ani-ani.

${ }^{20}$ Terjemahan tale tersebut adalah: Tidak hilir tidak bertuan/ sungguh ke hilir ke muara tebo/ tidak betale tidak bertuan/ sungguh betale hatiku iba/ bagaimana cara memasak ini/ beras manis bercampur 


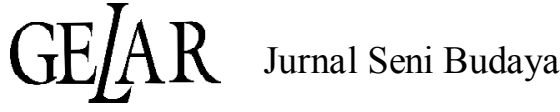

dengan padi kosong/ bagaimana hatiku ini/ tertawa bercampur dengan tangis/ hilir mudik menyandang jangki/ jangki berisi si benang kain/ hilir mudik saudara benci/ kemana badan tempat mengadu

${ }^{21}$ Tale joi juga memiliki sebutan lain seperti tale ji dan tale naik ji

${ }^{22}$ Terjemahan tale tersebut adalah: Dengan Bismillah mulai betale/mulai berdo'a dengan lafaz Alhamdulilah/ melembutkan tale dengan laillahaillallah/ shalawat nabi tidak boleh lupa/ tiga negeri yang dilebihkan Allah/ pertama Mekah kedua Madinah/ Baitullah magdis tempat ketiga/ rukun kelima haji ke Baitullah.

${ }^{23}$ Kenduri sko singkatan dari kenduri pusaka. Acara adat yang dilakukan oleh masyarakat Kerinci terkait dengan pusaka dari nenek moyang.

${ }^{24}$ Gumbe merupakan gendang yang terbuat dari bambu tua.

${ }^{25}$ Dap merupakan rebana besar khas Kerinci

${ }^{26}$ Tale mantau artinya memanggil dengan suara yang melengking dan lantang

${ }^{27}$ Terjemahan tale tersebut adalah:

Pemuda: Coba-coba kerisik menjulai/ agar tentu padi dengan genta/ coba-coba bercanda dengan kami/ agar tentu budi dengan basa.

Pemudi: Sudah lama kami hendak ke koto/ ke koto menjelang pagi/ sudah lama kami menanti kata tuan/ baru sekarang terobat hati.

${ }^{28}$ Terjemahan tale tersebut adalah: Bagus tari anda semua ini/ ayunlah jari sampai jatuh/ rentak kaki kuda berlari/ semut terinjak tidak mati.

${ }^{29}$ Terjemahan tale tersebut adalah: Mula-mula kami duduk/ kami duduk sesudah bersiang/ mula-mula kami merangguk/ kami merangguk untuk bapak yang datang/ ramai orang di tanjung tanah/ orang seleman menjual tangguk/ kami susun jari angkat sembah/ beri maaf kami hendak merangguk.

${ }^{30}$ Ensambel yang dimaksud yaitu enasambel campuran, yaitu sajian musik yang menggunakan beberapa alat musik. Prier dalam Kamus Musik (2009, 42) menuliskan bahwa ensambel berarti bersama; kerjasama. Istilah ensambel digunakan untuk kelompok pemain alat musik dalam jumlah terbatas. Dalam tulisannya Prier menuliskan bahwa 'orkes keroncong', 'orkes kolintang', merupakan istilah yang kurang tepat. Maka penggunaan kata ensambel pada musik Seruling Bambu dirasa tepat.

\section{KEPUSTAKAAN}

Danandjaja, James. 2007. Folklor Indonesia, IImu Gosip, Dongeng, dan lain- lain. Jakarta: Grafiti

Mistortoify, Zulkarnaen. 2015. "Ong-Klaongan dan LeKalellean Estetika Kejhungan Orang Madura Barat". Disertasi. Universitas Gajah Mada.

Moleong, Lexi. 2000. Metode Penelitian Kualitatif. Bandung: Remaja Rosdakarya.

Peursen, Van C. A. 1976. Strategi Kebudayaan. Yogyakarta: Kanisius.

Prier, Karl-Edmund. 2011. Kamus Musik: Yogyakarta. Pusat Musik Liturgi.

Rohidi, Rohendi, Tjetjep. 2000. Kesenian Dalam Pendekatan Kebudayaan. Bandung: STISI Press.

Sari, Ayuthia Mayang. 2018. "Konsep dan Capaian Estetis Tale dalam Pertunjukan Seruling Bambu di Kerinci, Jambi”. Tesis. Institut Seni Indonesia Surakarta.

Sugiarto, Eko. 2015. Mengenal Sastra Lama. Yogyakarta: ANDI Yogyakarta.

Sutiyono. 2011. Fenomenologi Seni. Yogyakarta: Insan Persada.

Zakaria, Iskandar. 1984.Tambo Sakti Alam Kerinci. Jakarta: Departemen Pendidikan dan Kebudayaan. 